\title{
Functional Anatomy of the Mental Representation of Upper Extremity Movements in Healthy Subjects
}

\author{
K. M. STEPHAN, G. R. FINK, R. E. PASSINGHAM, D. SILBERSWEIG, A. O. CEBALLOS-BAUMANN, \\ C. D. FRITH, AND R. S. J. FRACKOWIAK \\ Wellcome Department of Cognitive Neurology, Institute of Neurology and Medical Research Council Cyclotron Unit, \\ Hammersmith Hospital, London W12 ONN, United Kingdom; Neurologisches Therapiecentrum an der Universität, \\ Dusseldorf; Max-Planck-Institut für Neurologische Forschung, Cologne, Germany; Department of Experimental \\ Psychology, Oxford, United Kingdom; Department of Psychiatry, The New York Hospital, New York; Neurologische \\ Klinik der Technischen Universität, Munich, Germany; Department of Psychology, University College London
}

\section{SUMMARY AND CONCLUSIONS}

1. Differences in the distribution of relative regional cerebral blood flow during motor imagery and execution of a joy-stick movement were investigated in six healthy volunteers with the use of positron emission tomography (PET). Both tasks were compared with a common baseline condition, motor preparation, and with each other. Data were analyzed for individual subjects and for the group, and areas of significant flow differences were related to anatomy by magnetic resonance imaging (MRI).

2. Imagining movements activated a number of frontal and parietal regions: medial and lateral premotor areas, anterior cingulate areas, ventral opercular premotor areas, and parts of superior and inferior parietal areas were all activated bilaterally when compared with preparation to move.

3. Execution of movements compared with imagining movements led to additional activations of the left primary sensorimotor cortex and adjacent areas: dorsal parts of the medial and lateral premotor cortex; adjacent cingulate areas; and rostral parts of the left superior parietal cortex.

4. Functionally distinct rostral and caudal parts of the posterior supplementary motor area (operationally defined as the SMA behind the coronal plane at the level of the anterior commissure) were identified. In the group, the rostral part of posterior SMA was activated by imagining movements, and a more caudoventral part was additionally activated during their execution. A similar dissociation was observed in the cingulate areas. Individual subjects showed that the precise site of these activations varied with the individual anatomy; however, a constant pattern of preferential activation within separate but adjacent gyri of the left hemisphere was preserved.

5 . Functionally distinct regions were also observed in the parietal lobe: the caudal part of the superior parietal cortex [medial Brodmann area (BA) 7] was activated by imagining movements compared with preparing to execute them, whereas the more rostral parts of the superior parietal lobe (BA 5), mainly on the left, were additionally activated by execution of the movements.

6 . Within the operculum, three functionally distinct areas were observed: rostrally, prefrontal areas (BA 44 and 45) were more active during imagined than executed movements; a ventral premotor area (BA 6) was activated during both imagined and executed movements; and more caudally in the parietal lobe, an area was found that was mainly activated by execution, presumably SII.

7. These data suggest that imagined movements can be viewed as a special form of "motor behavior" that, when compared with preparing to move, activate areas associated heretofore with selection of actions and multisensory integration. The neural substrate of imagining a movement differs from that involved in its execution most notably by the absence of activation of the primary sensorimotor cortex in the central sulcus and immediately adjacent premotor, cingulate, and parietal structures.

\section{INTRODUCTION}

Mental rehearsal of movement is a common technique used by musicians and sportsmen to improve their performance. Experience and experimental studies suggest that imagining movements aids motor skill acquisition (Hall et al. 1992; Yue and Cole 1992). The physiological basis for this process is not well understood. Motor imagery may be functionally close to motor preparation. Some authors suggest that imagined movements are closely related to actual movements and share, at least in part, a common physiological substrate (e.g., Kohl and Roenker 1989).

One approach to this question is to use functional imaging to study the functional anatomy of imagined movements. In 1980, Roland et al. showed that during a motor sequence task with simple finger movements the contralateral primary motor and sensory areas and bilateral supplementary motor area (SMA) were primarily activated. During mental rehearsal of the same movement, only SMA was activated. In a later study Decety et al. (1988) observed additional activation of cerebellar structures during imaginary execution of more complex movements. Using functional magnetic resonance imaging (MRI), Rao et al. (1993) have recently shown that lateral premotor areas can also be involved in imagining movements. In contrast to those findings, which excluded the primary motor areas, Lang et al. (1994) have demonstrated recently that imagining saccades leads also to activation of precentral gyrus, representing the frontal eye fields (FEF).

The first aim of our study was to compare motor imagery with both motor preparation and motor performance. We were interested to know whether we could observe activity in medial and lateral premotor and parietal areas over and above the activity already present during motor preparation. We chose therefore a well-standardized task, the free selection of joy-stick movements, which is known to produce large regional cerebral blood flow ( $\mathrm{rCBF}$ ) changes in SMA and extensive lateral premotor and parietal areas (Deiber et al. 1991). This task also allowed us to ask whether areas of 
the brain beyond the primary sensori-motor cortex also show differences in activity when movements are imagined or executed.

Second, we were intrigued by our observations in patients who had suffered brain injury and limb paralysis, but had recovered motor function. Making movements with the recovered limb was associated with activations in areas additional to those normally activated by motor tasks, namely, in ventral premotor [Brodmann area (BA) 6] and ventral rostral parietal (BA 40) areas (Chollet et al. 1991; Weiller et al. 1992, 1993). We have found similar patterns in patients with motorneuron disease who performed the same motor task with the whole limb and in whom activations were compared with those elicited in normal subjects (Kew et al. 1993). Because little is known about the human motor physiology of these ventral premotor and parietal areas, we were especially interested in their patterns of activation.

\section{METHODS}

We studied six healthy male subjects (mean age $47 \mathrm{yr}$; range 29-66). None had a history, symptoms, or signs of neurological or psychiatric disease. All were right-handed as measured by a short questionnaire based on the Edinburgh Medical Research Council handedness scale (Oldfield 1971; Schachter et al. 1987). All subjects gave informed written consent. The study was approved by the Hammersmith Hospital Medical Ethics Committee, and permission to administer radioactivity was obtained from the Administration of Radioactive Substances Advisory Committee of the Department of Health, United Kingdom.

All subjects underwent 12 perfusion scans with positron emission tomography (PET) over the course of a 3-h session with the use of radioactive counts as an index of relative $\mathrm{rCBF}$, which is an indicator of neuronal activity (Raichle et al. 1987). They were asked to perform one of the following three tasks during each 90s scan: execution of a sequence of joy-stick movements; imagined execution of such a sequence of joy-stick movements; or preparing to perform one of these movements. The order of the scans was counterbalanced to control for any order effects.

During the three tasks, movements of the right arm and hand were monitored visually and with continuous surface electromyograph (EMG) of the right thenar eminence. Direction and amplitude of joy-stick movements were monitored with the use of a microcomputer. The task was repeated outside the PET scanner in two subjects to obtain a detailed picture of muscle activity in each of the three tasks. Seven muscle groups were monitored with surface EMG: first dorsal interosseus, thenar eminence, flexor digitorum superficialis, extensor digitorum communis superficialis and biceps on the right side, and the first dorsal interosseus and biceps on the left. In these experiments subjects performed the three tasks in the same order as during PET scanning.

1) Execution. During scanning, subjects were asked to perform sequential joy-stick movements in any of four different directions. They could choose these directions freely but were asked not to perform very long sequences of movements in the same direction. Movements were externally paced at 2 per $3 \mathrm{~s}$ by an auditory stimulus. Subjects used a joy-stick that centered automatically; they were told to return to this neutral position without delay, so that they could "start" the next movement as soon as they heard the next tone. Performance started $\sim 10 \mathrm{~s}$ before radiolabeled water $\left[\mathrm{H}_{2}{ }^{15} \mathrm{O}\right.$-a tracer of perfusion; $\left.t_{1 / 2}\left({ }^{15} \mathrm{O}\right)=2.1 \mathrm{~min}\right]$ reached the brain and was continued for $120 \mathrm{~s}$. This starting time was determined by monitoring the counts registered from the whole head by the scanner per second.

2) Imagining. Subjects were asked to imagine the same move- ments as described above (including the movement back to the central position) without actually performing them and without cuing themselves verbally. They had no prior training except for five or six imagined "trial movements" to help them understand the task. Again, imagined movements were externally paced at 2 per $3 \mathrm{~s}$ and were started $\sim 10 \mathrm{~s}$ before the arrival of radioactivity in the brain. If any muscle activity different from the control state (see below) was noted on EMG during the first few seconds of the task, subjects were reminded verbally to imagine and not to perform the movements. To maximize attention and compliance with the task, subjects were informed beforehand that they would be asked at the end of the scan in which direction the last imagined movement had been made.

3) Motor preparation. Subjects were asked to prepare to move during the time the scan was performed. To achieve this aim they were instructed to move once in a direction of their choice, as quickly as possible, when touched on the right arm. The same auditory tone was administered at the same rate as in the other two conditions. Subjects were specifically reminded not to perform or imagine movements when hearing a tone. They were touched two or three times during the experimental period, but not during the scan itself.

\section{Data acquisition}

All six subjects had T1 weighted MRI scans (1 Tesla Picker HPQ Vista system, radiofrequency spoiled volume acquisition, repeat time $24 \mathrm{~ms}$, echo time $6 \mathrm{~ms}$, nonselective excitation with a flip angle of $35^{\circ}$, field of view in plane $25 \times 25 \mathrm{~cm}, 192 \times$ 256 in plane matrix with 128 secondary phase encoding steps oversampled to 256 , resolution $1.3 \times 1.3 \times 1.5 \mathrm{~mm}$, total imaging time $20 \mathrm{~min}$ ) to visualize anatomy for comparison with individual activation maps. The PET scans were performed with the use of a CTI/Siemens 953B PET scanner (CTI, Knoxville, TN) with removable septa. The scanner collects data from 16 rings of bismuth germanate crystal detectors giving an axial field of view of $10.65 \mathrm{~cm}$. The distribution of cerebral radioactivity was recorded for $90 \mathrm{~s}$, in 3D mode with scanner interplane septa retracted (Townsend et al. 1991), after a slow bolus injection of $\mathrm{H}_{2}{ }^{15} \mathrm{O}$ through a venous line in the left arm (Silbersweig et al. 1993). Emission data were corrected for effects of tissue attenuation by the use of measurements from a transmission scan $\left({ }^{68} \mathrm{Ga} /{ }^{68} \mathrm{Ge}\right.$ sources), which was performed before the activation scans. PET data were reconstructed into 31 planes with the use of a Hanning filter with a cutoff frequency of $0.5 \mathrm{cycles} / \mathrm{s}$. The resolution of the resulting images was $8.5 \times 8.5 \times 4.3 \mathrm{~mm}$ at full-width half-maximum (FWHM) (Spinks et al. 1992).

In all subjects the field of view included the vertex. As the axial field of view was restricted to $10.65 \mathrm{~cm}$, the lowest parts of the frontal and occipital lobe, the lower temporal lobe, and most of the cerebellum were excluded from the field of view. To ensure that activations were not reported in areas that were outside the field of view common to all subjects, no activations were reported below a $z$-coordinate of -8 in Talairach space.

\section{Data analysis}

Data were analyzed for the group of subjects by intersubject averaging and also for each individual subject separately. The former analysis provided information about regional changes in the distribution of relative blood flow that were common to the members of the group. Individual analysis provided information relevant to investigation of structure-function relationships and their individual variability.

For group analysis the MRI scans were all aligned parallel to the intercommissural line (AC-PC line) and resized into the standard anatomic space of the atlas of Talairach and Tournoux (1988) with 
TABLE 1. Talairach coordinates of maxima of activation for imagined and executed movements compared with preparation to move as the control condition

\begin{tabular}{|c|c|c|c|c|c|c|c|c|c|}
\hline \multirow[b]{2}{*}{ Anatomic Areas } & \multirow[b]{2}{*}{ Hemisphere } & \multicolumn{4}{|c|}{$\begin{array}{l}\text { Imagined Movement Vs. Motor } \\
\text { Preparation }\end{array}$} & \multicolumn{4}{|c|}{$\begin{array}{l}\text { Executed Movement Vs. Motor } \\
\text { Preparation }\end{array}$} \\
\hline & & $x$ & $y$ & $z$ & $z$-value & $x$ & $y$ & $z$ & $z$-value \\
\hline \multirow[t]{2}{*}{ Anterior SMA } & $\mathbf{L}$ & & & & & & & & \\
\hline & $\mathbf{R}$ & & & & & 4 & 12 & 64 & 4.6 \\
\hline \multirow[t]{4}{*}{ Posterior SMA and inferior medial wall } & $\mathrm{L}$ & 0 & -12 & 60 & 5.7 & -6 & -10 & 68 & 3.9 \\
\hline & & & & & & 0 & -10 & 52 & 7.9 \\
\hline & $\mathbf{R}$ & 0 & -12 & 60 & 5.7 & 8 & -16 & 60 & 5.6 \\
\hline & & 6 & -8 & 52 & 6.2 & & & & \\
\hline \multirow[t]{3}{*}{ Cingulate area } & $\mathrm{L}$ & 0 & 2 & 48 & 4.6 & $\begin{array}{l}-2 \\
-2\end{array}$ & $\begin{array}{r}-2 \\
-18\end{array}$ & $\begin{array}{l}40 \\
44\end{array}$ & $\begin{array}{l}5.0 \\
6.2\end{array}$ \\
\hline & & & & & & -8 & $\begin{array}{l}-10 \\
-30\end{array}$ & $\begin{array}{l}44 \\
44\end{array}$ & $\begin{array}{l}0.2 \\
4.8\end{array}$ \\
\hline & $\mathrm{R}$ & & & & & 12 & -10 & 36 & 4.1 \\
\hline \multirow{5}{*}{$\begin{array}{l}\text { Dorsal lateral premotor area (supcrior } \\
\text { frontal gyrus) }\end{array}$} & $\mathbf{L}$ & -16 & -10 & 64 & 3.9 & & & & \\
\hline & & -12 & -26 & 60 & 3.9 & -16 & -14 & 60 & 8.0 \\
\hline & & -12 & -18 & 56 & 4.0 & -16 & -20 & 56 & 7.6 \\
\hline & $\mathbf{R}$ & & & & & 16 & -16 & 64 & 5.6 \\
\hline & & & & & & 18 & -16 & 56 & 6.0 \\
\hline \multirow{2}{*}{$\begin{array}{l}\text { Lateral premotor area (close to lateral } \\
\text { wall of superior frontal gyrus) }\end{array}$} & $\mathrm{L}$ & -14 & -12 & 48 & 5.0 & -18 & -14 & 52 & 6.1 \\
\hline & $\mathbf{R}$ & 22 & -12 & 52 & 3.8 & 24 & -14 & 52 & 5.1 \\
\hline \multirow{4}{*}{$\begin{array}{l}\text { Ventral oprcular premotor area } \\
\text { (venterolateral area 6) }\end{array}$} & L & -44 & 4 & 16 & 4.9 & & & & \\
\hline & & -36 & 4 & 12 & 5.7 & -40 & 0 & 12 & 5.7 \\
\hline & $\mathbf{R}$ & & & & & 46 & 4 & 16 & 4.2 \\
\hline & & 40 & 0 & 12 & 4.2 & 38 & 0 & 12 & 5.3 \\
\hline \multirow[t]{5}{*}{ Precentral gyrus (laterorostral part) } & $\mathbf{L}$ & -40 & -10 & 48 & 4.7 & & & & \\
\hline & & -40 & -10 & 40 & 4.0 & & & & \\
\hline & & -32 & -16 & 52 & 4.0 & & & & \\
\hline & & -36 & -18 & 44 & 4.7 & & & & \\
\hline & $\mathbf{R}$ & 44 & -10 & 44 & 3.9 & & & & \\
\hline \multirow[t]{4}{*}{ Precentral and postcentral gyrus } & $\mathrm{L}$ & & & & & -22 & -22 & 68 & 5.7 \\
\hline & & & & & & -26 & -20 & 64 & 5.2 \\
\hline & & & & & & -28 & -26 & 52 & 10.4 \\
\hline & $\mathbf{R}$ & & & & & 26 & -32 & 56 & 3.8 \\
\hline \multirow[t]{2}{*}{ Superior parietal area (Brodmann area 5) } & $\mathbf{L}$ & & & & & -30 & -44 & 52 & 7.2 \\
\hline & $\overline{\mathbf{R}}$ & & & & & 34 & -36 & 52 & 4.9 \\
\hline \multirow[t]{2}{*}{ Superior parietal area (Brodmann area 7) } & $\mathrm{L}$ & -26 & -62 & 48 & 3.8 & -22 & -58 & 56 & 5.0 \\
\hline & $\mathbf{R}$ & & & & & 24 & -56 & 56 & 4.6 \\
\hline \multirow[t]{4}{*}{ Precuneus (dorsocaudal Brodmann area 7) } & $\mathbf{L}$ & & & & & -16 & -62 & 52 & 4.6 \\
\hline & & & & & & -16 & -72 & 40 & 4.4 \\
\hline & $\mathbf{R}$ & 14 & -70 & 44 & 4.9 & 16 & -60 & 52 & 5.6 \\
\hline & & & & & & 16 & -66 & 44 & 4.8 \\
\hline \multirow[t]{6}{*}{ Inferior parietal lobe (dorsal area 40) } & $\mathbf{L}$ & -28 & -44 & 40 & 5.2 & -32 & -44 & 44 & 6.8 \\
\hline & & & & & & -22 & -54 & 48 & 5.2 \\
\hline & & & & & & -20 & -50 & 36 & 4.2 \\
\hline & $\mathbf{R}$ & 34 & -38 & 40 & 5.3 & 28 & -48 & 44 & 5.6 \\
\hline & & 30 & -50 & 44 & 4.1 & 32 & -36 & 40 & 6.5 \\
\hline & & & & & & 36 & -48 & 36 & 4.0 \\
\hline \multirow[t]{3}{*}{ Inferior parietal lobe (rostral area 40 ) } & $\mathrm{L}$ & -46 & -22 & 32 & 3.9 & -42 & -24 & 36 & 7.1 \\
\hline & & & & & & -46 & -32 & 28 & 4.4 \\
\hline & $\mathbf{R}$ & 46 & -22 & 36 & 4.5 & 46 & -22 & 36 & 6.9 \\
\hline \multirow[t]{2}{*}{ Ventral inferior parietal area (SII) } & $\mathrm{L}$ & -44 & -14 & 24 & 4.2 & -42 & -22 & 20 & 5.8 \\
\hline & $\mathbf{R}$ & & & & & 50 & -18 & 20 & 4.4 \\
\hline Insula & $\mathbf{L}$ & -28 & 10 & 4 & 4.6 & & & & \\
\hline Cerebellum & & & & & & 4 & -52 & -4 & 4.5 \\
\hline
\end{tabular}

A Bonferroni-like correction for multiple nonindependant comparisons and a threshold of $P<0.05$ were used (mean $z$ threshold 3.7). SMA, supplementary motor area; L, left; R, right.

the use of the same linear and nonlinear algorithms and transformation matrices as were used for the PET data (see below). The scans were then averaged, to provide a mean MRI scan in which there were sufficient details to identify major anatomic landmarks. The blurring in the mean MRI scan reflects the variability in position of anatomic structures for our group of individuals. This average MRI scan in Talairach space served as a template onto which the average PET data were overlaid in the group analysis for localization of group activations. This procedure allowed us to report activated foci in terms of Talairach and Tournoux coordinates as well as by reference to anatomic structures.

To prepare the PET data for analysis, each scan in a series of 12 recorded from an individual was 1 st relocated, with the use of Automated Image Registration software (AIR) (Woods et al. 
upper limb movements: whole group imagining vs preparation


$$
+12
$$

$+20$

$$
+28
$$
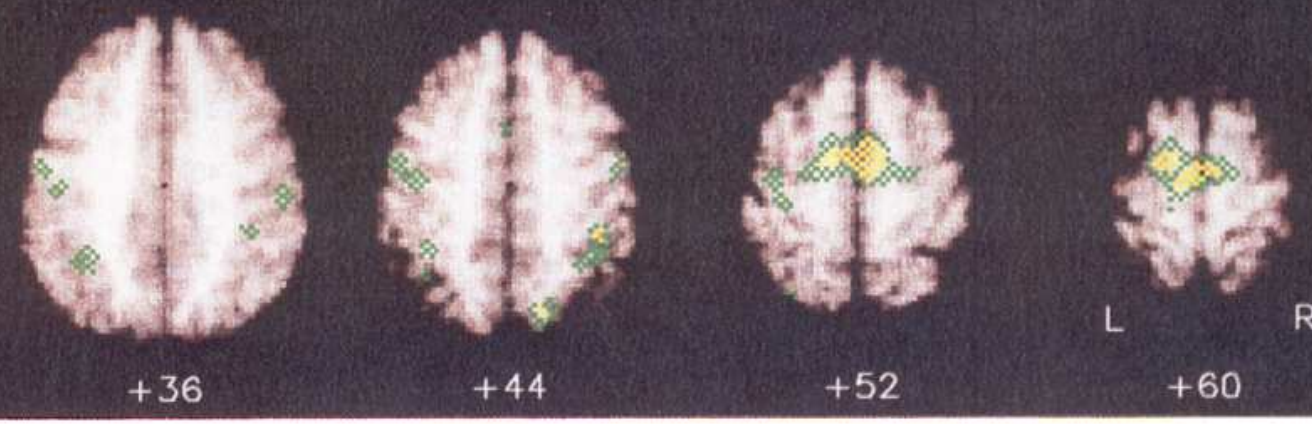

Fig. 1

upper limb movements: whole group execution vs imagining
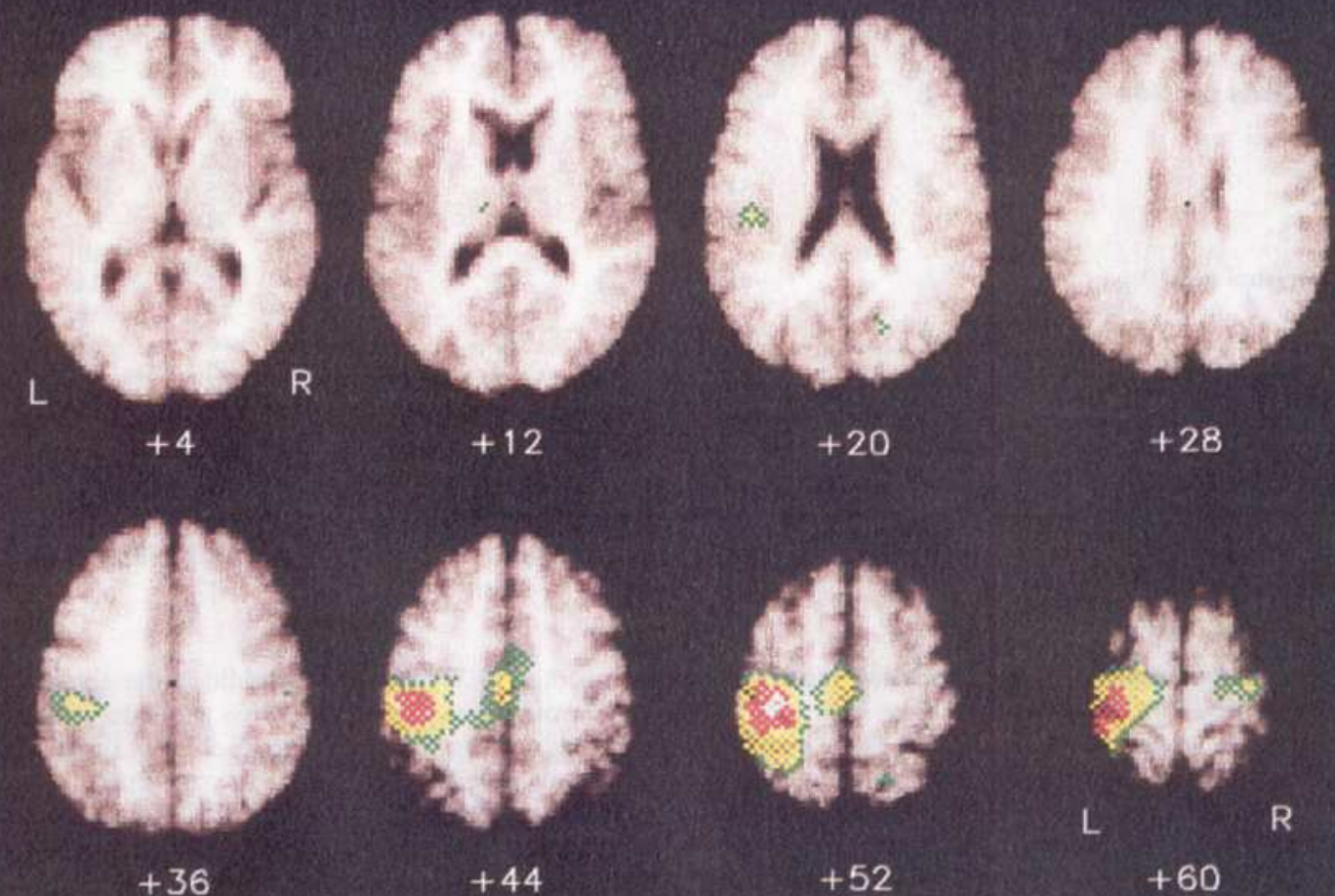

Fig. 2 
TABLE 2. Talairach coordinates of maxima of activation for actual movement compared with imagined movement as the control condition and for imagined movement compared with actual movement as a control condition

\begin{tabular}{|c|c|c|c|c|c|c|c|c|}
\hline \multirow[b]{2}{*}{ Anatomic Areas } & \multicolumn{4}{|c|}{ Left Hemisphere } & \multicolumn{4}{|c|}{ Right Hemisphere } \\
\hline & $x$ & $y$ & $z$ & $z$-value & $x$ & $y$ & $z$ & $z$-value \\
\hline \multicolumn{9}{|c|}{ Executed versus imagined movements } \\
\hline Posterior SMA & -8 & -20 & 56 & 5.4 & & & & \\
\hline Cingulate area & $\begin{array}{l}-2 \\
-4\end{array}$ & $\begin{array}{l}-20 \\
-30\end{array}$ & $\begin{array}{l}48 \\
44\end{array}$ & $\begin{array}{l}6.7 \\
4.7\end{array}$ & $\begin{array}{l}2 \\
8\end{array}$ & $\begin{array}{l}-6 \\
-8\end{array}$ & $\begin{array}{l}44 \\
40\end{array}$ & $\begin{array}{l}4.3 \\
3.9\end{array}$ \\
\hline Dorsal lateral premotor area & $\begin{array}{l}-22 \\
-16\end{array}$ & $\begin{array}{l}-24 \\
-24\end{array}$ & $\begin{array}{l}64 \\
60\end{array}$ & $\begin{array}{l}6.3 \\
6.2\end{array}$ & 16 & -18 & 64 & 4.9 \\
\hline Precentral and postcentral gyrus & $\begin{array}{l}-28 \\
-28 \\
-34\end{array}$ & $\begin{array}{l}-22 \\
-26 \\
-28\end{array}$ & $\begin{array}{l}60 \\
52 \\
44\end{array}$ & $\begin{array}{l}7.1 \\
9.0 \\
8.3\end{array}$ & $\begin{array}{l}28 \\
30\end{array}$ & $\begin{array}{l}-20 \\
-18\end{array}$ & $\begin{array}{l}60 \\
56\end{array}$ & $\begin{array}{l}4.9 \\
4.0\end{array}$ \\
\hline $\begin{array}{l}\text { Superior parietal area } \\
\text { (Brodmann area 5) }\end{array}$ & -30 & -44 & 52 & 6.4 & & & & \\
\hline $\begin{array}{l}\text { Superior parietal area } \\
\text { (Brodmann area 7) }\end{array}$ & -16 & -48 & 48 & 3.8 & 16 & -58 & 52 & 4.4 \\
\hline $\begin{array}{l}\text { Inferior parietal lobe (dorsal } \\
\text { area 40) }\end{array}$ & & & & & 32 & -36 & 48 & 3.9 \\
\hline $\begin{array}{l}\text { Inferior parietal lobe (rostral } \\
\text { area 40) }\end{array}$ & -40 & -26 & 36 & 5.1 & 46 & -20 & 32 & 4.1 \\
\hline $\begin{array}{l}\text { Ventral inferior parietal area } \\
\text { (SII) } \\
\text { Thalamus }\end{array}$ & $\begin{array}{l}-38 \\
-10\end{array}$ & $\begin{array}{l}-22 \\
-18\end{array}$ & $\begin{array}{l}20 \\
12\end{array}$ & $\begin{array}{l}4.9 \\
3.8\end{array}$ & & & & \\
\hline \multicolumn{9}{|c|}{ Imagined versus executed movements } \\
\hline $\begin{array}{l}\text { Caudal inferior frontal cortex } \\
\text { Dorsolateral prefrontal cortex } \\
\text { Middle temporal lobe }\end{array}$ & $\begin{array}{l}-44 \\
-40 \\
-56\end{array}$ & $\begin{array}{r}16 \\
30 \\
-44\end{array}$ & $\begin{array}{r}12 \\
8 \\
-4\end{array}$ & $\begin{array}{l}4.6 \\
3.9 \\
5.1\end{array}$ & & & & \\
\hline
\end{tabular}

Corrections for multiple nonindependant comparisons and a threshold of $P<0.05$ were used (mean $z$ threshold 3.6). SMA, supplementary motor area.

1992), so that all scans were spatially congruent with the 1 st recorded scan. For the group study, mean PET scans of each individual were coregistered with their individual MRI to identify the AC-PC plane (Woods et al. 1993). Then all PET scans were resized, with the use of linear and nonlinear algorithms and additional information from the MRIs, into the standard anatomic space of Talairach and Tournoux (Friston et al. 1991a; Watson et al. 1993).

For individual analyses, MRI scans were kept in their original size to preserve information on the exact anatomy. MRI scans were reoriented to lie parallel to the AC-PC line. Then PET scans were coregistered with MRI scans (Woods et al. 1993) to provide a transformation matrix. This matrix was subsequently used to coregister statistical maps of significant blood flow change for each individual with the appropriate MRI scan.

PET images were filtered with the use of a low-pass Gaussian filter (FWHM $10 \times 10 \times 12 \mathrm{~mm}$ ) in 3D to reduce noise and maximize signal (Friston et al. 1990, 1991a). Maps of conditionspecific average cerebral blood flow were generated with the use of a pixel-based analysis of covariance (ANCOVA). This procedure uses all the scans from all subjects for each condition and covaries local pixel blood flow against average blood flow for each repeated measure over the whole data set. Regression of local on global flow generates an average pixel blood flow value that is normalized to an arbitrary relative global flow of $50 \mathrm{ml} / 100 \mathrm{ml} /$ min. An estimate of the error variance of the adjusted mean pixel flow for each condition is obtained by a sum of squares of the data points from the calculated regression line.

Blood flow changes between the conditions were then assessed with the use of $t$-statistics with appropriate weighting of the adjusted condition-specific values. The results are presented as sets of spatially distributed $z$-values that constitute statistical parametric maps (SPM $\{\mathrm{t}\}$ ), thresholded to a value of $P<0.05$ (corrected for multiple nonindependent comparisons) (Friston et al. 1991b). SPM $\{t\}$ maps identify the site of areas of statistically significant blood flow change occurring as a result of the differences in relative perfusion between task conditions.

Each individual focus reported represents a significant activation in its own right. Two foci are always separated by "subthreshold valleys." Fox et al. (1986) have shown that differences in position in subtracted scans as small as $2-3 \mathrm{~mm}$ can represent meaningful physiological differences. As a conservative estimate, we have chosen to describe two foci as different areas, when the distance between them was at least $10 \mathrm{~mm}$.

For individual studies, PET data were analyzed identically to the group data, but separately for each individual. Because only 4 repeated measures, rather than 24 , were available for the construction of each condition-specific mean blood flow map, we restricted the analysis to those areas that had shown significant activations

FIG. 1. Group positron emission tomography (PET) for imagined joy-stick movements vs. movement preparation superimposed on group magnetic resonance imaging (MRI). MRI slices are orientated parallel to the AC-PC line and shown every $8 \mathrm{~mm}$ starting at $4 \mathrm{~mm}$ above the AC-PC line. The left of the brain is to the left and anterior at the top. The colored regions represent areas in which activation results in changes of blood flow that exceed the statistical threshold of $P<0.05$ for multiple nonindependent comparisons. The colors represent different ranges of $z$-values: green, $z>3.6$ and $z \leq 4$; yellow, $z>4$ and $z \leq 5.5$; red, $z>5.5$ and $\leq 7$; and white, $z>7$.

FIG. 2. PET activations of the comparison executed vs. imagined movements superimposed on mean MRI slices parallel to the AC-PC line (conventions as Fig. 1). 
upper limb movements: whole group execution vs preparation


$+20$

$+28$


$$
+36
$$

$+44$

$+52$

L

R

Fig. 3

anatomical variation in SMA and cingulate area in the 6 subjects
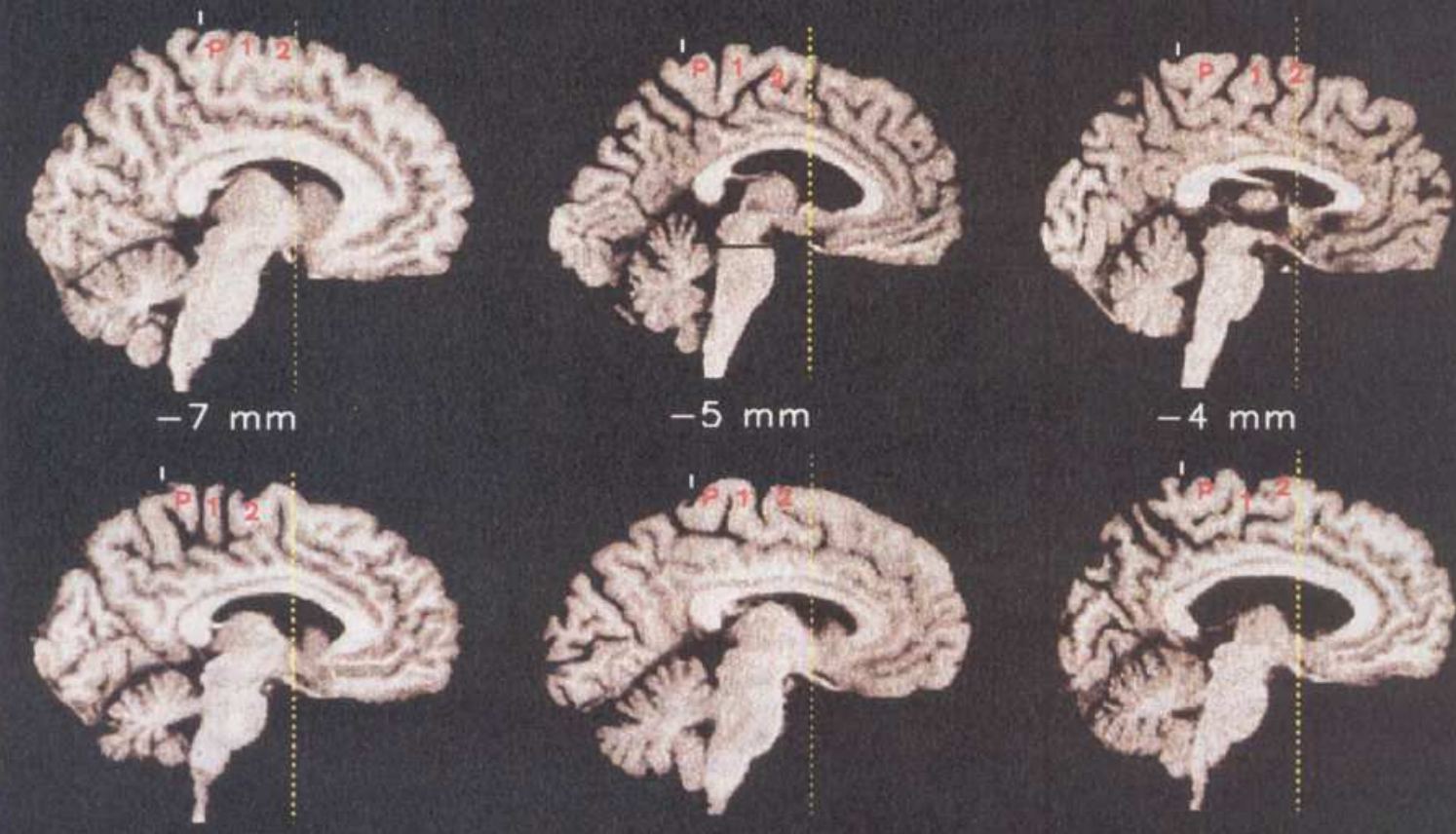

$-5 \mathrm{~mm}$

$-4 \mathrm{~mm}$

$-4 \mathrm{~mm}$

Fig. 4 
in the group study. Hence comparisons of these maps were thresholded to a level of $P<0.01$ ("omnibus" significance) (Friston et al. 1991b).

Data analysis was performed on Sun SPARC computers (Sun Microsystems, Mountain View, CA) with the use of ANALYZE (Mayo Foundation, Rochester, NY) (Robb 1990), MATLAB (The MathWorks, Natick, MA) and SPM software (MRC CU, London, UK).

\section{RESULTS}

\section{Performance measurements}

During all three conditions, subjects rested their arm and hand on a wooden bench while holding a joy-stick. Even when subjects were as relaxed as possible, and no movements were visible, some EMG activity was observed in the first dorsal interosseous muscle and the thenar eminence, presumably because of extension of the thumb during grip.

The movements of the joy-stick showed similar characteristics in terms of timing and distribution for all six subjects with no preference for any given direction. No movements were registered during preparation, nor with imagined movements.

During the PET scans, surface EMG showed bursts of activity during all executed movements. In two of the six subjects, a small degree of muscle activity was observed during preparation to move. EMG analysis was performed by visual comparison of the recorded EMG traces and showed that the amplitude and frequency of EMG activity were no higher during imagined movements than preparation of set. More detailed EMG recordings in two subjects outside the scanner confirmed that increased muscle activity in proximal and distal muscles can be part of preparational set, especially at the beginning of the scan. During imagined movements, muscle activity was still higher than at rest, but considerably lower than during preparation.

\section{Group results}

IMAGINED MOVEMENTS COMPARED WITH PREPARATION OF SET. When imagined movements were compared with motor preparation, there were significant increases of regional cerebral blood flow in medial and lateral premotor areas and in superior and inferior parietal areas bilaterally. Figure 1 gives an overview, showing the thresholded SPM $\{t\}$ maps superimposed onto the mean MRI image in Talairach space (Talairach and Tournoux 1988).

The top two planes in the figure demonstrate activation in the SMA and in lateral premotor areas $(+60$ and +52 $\mathrm{mm}$ above the AC-PC line; coordinates in Talairach space are provided for all activated areas in Table 1). Whereas the SMA covers, by definition, the medial wall of the superior frontal gyrus, the lateral premotor activations were situated on the dorsal surface and close to the lateral wall of the superior frontal gyrus (see Table 1 and Fig. 1). All activations were behind the $\mathrm{AC}$ line. The next two planes
( +44 and $+36 \mathrm{~mm}$ ) show bilateral activation of the ventrolateral part of the precentral gyrus and of the anterior cingulate gyrus. Bilateral activations were found in the superior parietal areas, in BA 7 on the left $(+52 \mathrm{~mm})$ and more posteriorly, in the area of the precuneus, on the right $(+44$ $\mathrm{mm}$ ). In the dorsal inferior parietal area close to the interparietal sulcus, activations were prominent in both hemispheres ( +44 and $+36 \mathrm{~mm}$; probably dorsal BA 40). A small area of activation in the rostral part of the inferior parietal lobes can be seen in planes +36 and $+28 \mathrm{~mm}$ (rostral BA 40 , close to the postcentral gyrus). Finally, planes +4 to +20 $\mathrm{mm}$ demonstrate activations of ventral opercular premotor areas bilaterally and in the insula on the left side.

EXECUTED COMPARED WITH IMAGINED MOVEMENTS. EXecution of movements led to additional activations of the left primary sensorimotor area and other closely associated areas Fig. 2, Table 2). Planes +36 to $+60 \mathrm{~mm}$ illustrate activation of the left primary sensorimotor cortex (activation peaks). The top planes demonstrate also activations of bilateral dorsal lateral premotor areas adjacent to the precentral gyrus $(+60 \mathrm{~mm})$ and of a part of the anterior cingulate area and SMA $(+44$ and +52 in Fig. $2,+40-48$ and +56 in Table $2)$. Within SMA and anterior cingulate, these areas are located more caudally than those activated during imagined movements (cf. Fig. 1 and Table 1).

In the superior parietal lobes, activations were observed more rostrally than during imagined movements (BA 5 on the left side at $+52 \mathrm{~mm}$ in Fig. 2 and bilateral BA 7 at +48 and +52 in Table 2 and Fig. 2). Additional inferior parietal activations were seen on the right (presumably dorsal BA $40,+48$ in Table 2 ), whereas more ventral and rostral activations of the inferior parietal lobe (rostral BA 40) were especially prominent on the left $(+36 \mathrm{~mm}$ in Fig. 2 , the activation shown includes activation peaks within BA 40 and the primary sensorimotor area). Finally, activations of the most ventral part of the inferior parietal lobe can be seen on plane $+20 \mathrm{~mm}$, with activation of the left thalamus on plane +12 mm (both Fig. 2).

EXECUTION OF MOVEMENTS COMPARED WITH MOTOR PREPARATION. Nearly all the activations described in the above two comparisons were seen when execution was directly compared with motor preparation (Table 1, Fig. 3): primary sensorimotor areas (planes +36 to +60 in Fig. 3), lateral premotor areas (planes +52 and +60 ), rostral and caudal parts of cingulate and medial premotor areas (planes +44 and +52$)$, activations in inferior and superior parietal areas (planes +36 to +52 ), and in the operculum (planes +12 and +20 , all Fig. 3 ). The group of areas activated by imagined movements forms an "outer ring" surrounding activations solely associated with the execution of movements. This "ring" is especially prominent in the lateral and medial premotor and in the superior parietal areas (planes +52 and +60 in Figs. 1-3). In the opercular premotor areas (planes +12 and +20 ), in the inferior parietal areas, and in the precuneus (planes +36 and $+44 \mathrm{~mm}$ ), the loci of activation

FIG. 3. PET activations of the comparison executed movements vs movement preparation superimposed on mean MRI slices parallel to the AC-PC line (conventions as Fig. 1).

FIG. 4. Left hemispheric sagittal slices of all 6 subjects, 4-7 mm from the midline. P, precentral gyrus; 1, 1st gyrus anterior to precentral gyrus; 2, 2nd gyrus anterior to precentral gyrus. The vertical tick (') indicates the position of the central sulcus, and the anterior line demonstrates the position of the AC line. For further explanations see text. 


\section{upper limb movements - individual subject I}

imagining vs

preparation

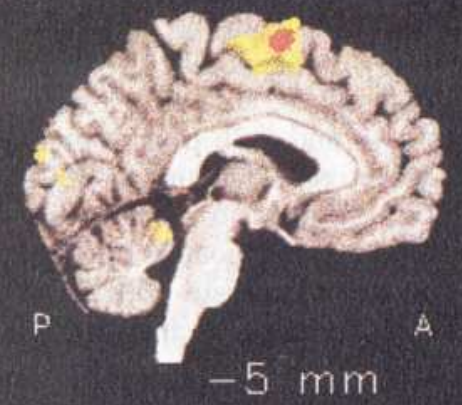

execution vs

imagining

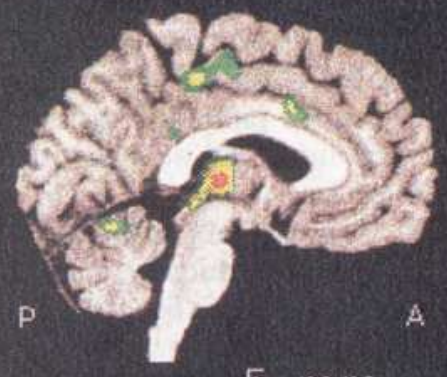

$-5 \mathrm{~mm}$


$-14 \mathrm{~mm}$



$+54 \mathrm{~mm}$

Fig. 5

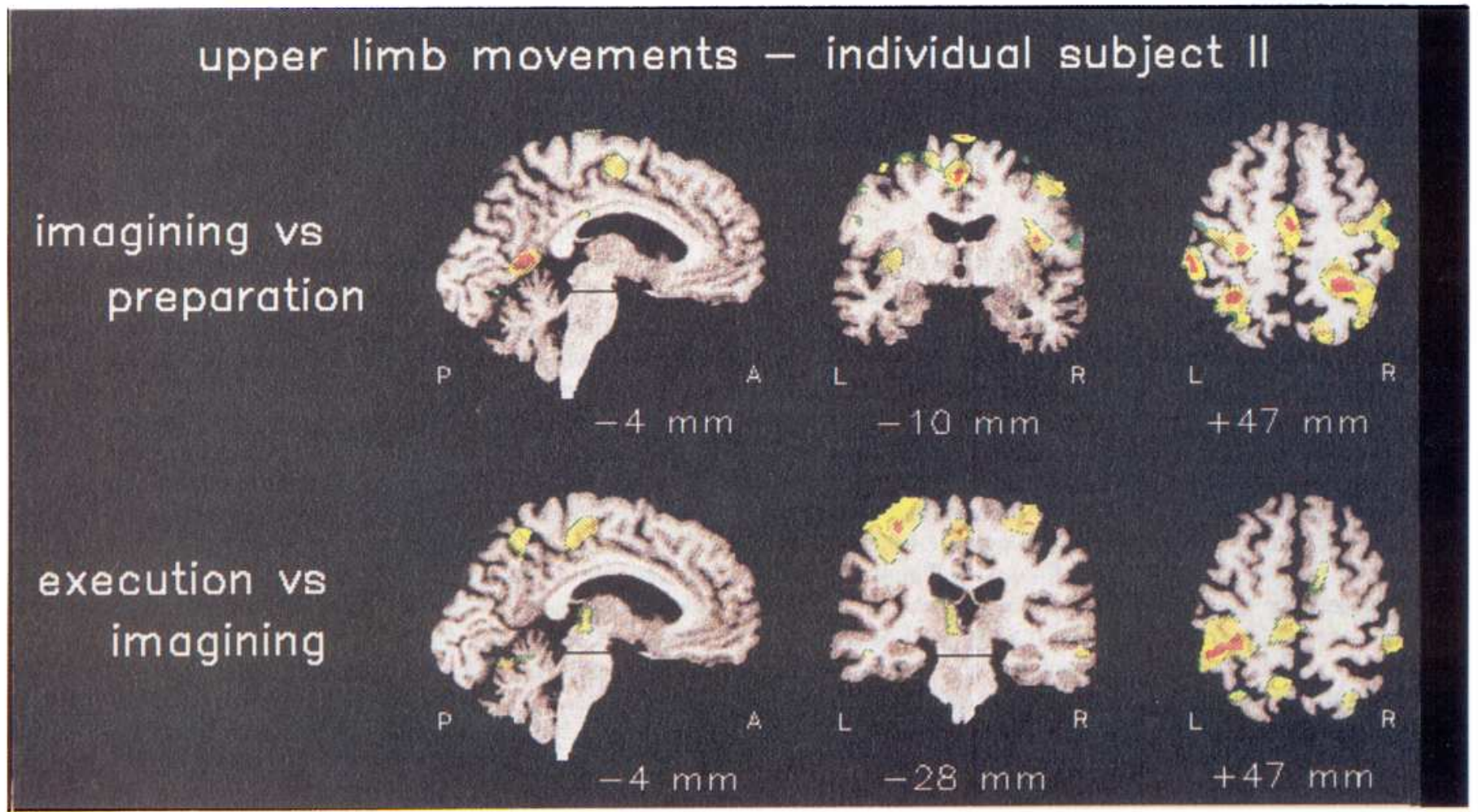

Fig. 6 
are similar for imagined and executed movements but are more significant (they show higher $z$-values) and often bilateral during movement execution (Table 1). Finally, Table 1 shows activation of the right side of the upper vermis of the cerebellum during movement execution.

IMAGINED MOVEMENTS COMPARED WITH EXECUTED MOVEMENTS. The comparison between imagined and executed movements showed three significant foci of activation, which are shown in Table 2: a ventral part of the dorsolateral prefrontal cortex (BA 46); caudal inferior frontal cortex (BA 44); and activations within the middle temporal gyrus. The activation in the middle temporal lobe shares its coordinates with a strong activation observed when movement preparation was compared with executed movements.

\section{Results in individual subjects}

Analysis of individual data defined the anatomy of activated areas in more detail and allowed assessment of interindividual variability. These results were of special interest for the medial wall of the superior frontal gyrus, as subjects showed variability (Fig. 4) within SMA and cingulate motor cortex.

In all subjects, we observed one cingulate sulcus, which had a direct connection to the parietal cortex via the marginal ramus (Fig. 4). In three subjects the sulcus was continuous in the left hemisphere; in the other three, there were two or more segments. In two of the subjects, we found an additional, nearly continuous second (top) cingulate sulcus in the left hemisphere. Several segments of such a second cingulate sulcus were present in three more subjects, and in only one subject was there solely one cingulate sulcus (all Fig. 4). Similarly, in the right hemisphere, four of the six subjects had either segments of, or a complete, "second" cingulate sulcus.

Foci of activation were mainly located in two areas, either in the dorsal part of the medial wall, or more ventrally, just above the (top) cingulate sulcus and/or between the two cingulate sulci. Examples of activations of those two sites are shown in Figs. 5 and 6 during imagery (top rows). Subject 1 showed a dorsal activation, subject 2 a more ventral activation. As in the group results, the additional foci of activation during execution of movements were also situated more posteriorly and ventrally in individuals (bottom rows, Figs. 5 and 6).

In the anterior-posterior direction the activations on the medial wall covered the area between the precentral sulcus ( $\mathrm{P}$ in Fig. 4) and the AC line. The posterior border was either the precentral sulcus, or an additional medial "precentral sulcus," which is sometimes found 1 to $2 \mathrm{~cm}$ anterior to the central sulcus (Ono et al. 1990). In four of the six subjects, the anterior border of the AC line coincided within a tolerance of $5 \mathrm{~mm}$ with another prominent sulcus. In five of the six subjects, the area in between could be further divided
TABLE 3. Number of subjects with foci of activity during imagining and performance of movements versus motor preparation

\begin{tabular}{|c|c|c|c|}
\hline & $\begin{array}{c}\text { Caudal } \\
\text { Posterior SMA }\end{array}$ & $\begin{array}{c}\text { Rostral } \\
\text { Posterior SMA }\end{array}$ & $\begin{array}{c}\text { Rostral or } \\
\text { Caudal }\end{array}$ \\
\hline \multicolumn{4}{|c|}{ Imagining } \\
\hline \multicolumn{4}{|l|}{ Left hemisphere } \\
\hline $\begin{array}{l}\text { Superior medial } \\
\text { wall } \\
\text { Inferior medial }\end{array}$ & & $5 / 6$ & $5 / 6$ \\
\hline wall/dorsal & $1 / 6$ & $2 / 6$ & $2 / 6$ \\
\hline cingulate & $1 / 6$ & $6 / 6$ & \\
\hline \multicolumn{4}{|l|}{ Right hemisphere } \\
\hline \multicolumn{3}{|l|}{ Superior medial } & $4 / 6$ \\
\hline \multicolumn{4}{|l|}{ Inferior medial } \\
\hline wall/dorsal & $1 / 6$ & $2 / 6$ & $3 / 6$ \\
\hline \multirow[t]{2}{*}{ cingulate } & $2 / 6$ & $3 / 6$ & \\
\hline & \multicolumn{2}{|c|}{ Performance } & \\
\hline \multicolumn{4}{|l|}{ Left hemisphere } \\
\hline \multicolumn{3}{|l|}{ Superior medial } & $4 / 6$ \\
\hline \multicolumn{4}{|l|}{ Inferior medial } \\
\hline wall/dorsal & $5 / 6$ & $3 / 6$ & $6 / 6$ \\
\hline cingulate & $6 / 6$ & $3 / 6$ & \\
\hline \multicolumn{4}{|l|}{ Right hemisphere } \\
\hline \multicolumn{3}{|l|}{ Superior medial } & $2 / 6$ \\
\hline \multicolumn{4}{|l|}{ Inferior medial } \\
\hline wall/dorsal & $3 / 6$ & $1 / 6$ & $3 / 6$ \\
\hline cingulate & $5 / 6$ & $3 / 6$ & \\
\hline
\end{tabular}

SMA, supplementary motor area.

into two gyri, marked with the numbers 1 and 2 in Fig. 4. The dividing sulcus showed a high degree of variability within the five subjects; in the sixth subject there were two small sulci, and it was difficult to identify the major one. In this subject the most anterior gyrus has been marked with number 2. A similar pattern of two gyri anterior to the precentral gyrus, but mainly posterior to the AC line, emerged for the right hemisphere.

This gyral pattern was the basis for a more detailed description of the location of activation foci (Table 3 ). In the left hemisphere the dorsal part of the second gyrus anterior to the precentral gyrus was mostly activated during imagery, whereas the first gyrus, especially its more ventral part, showed foci of activation mainly during movement execution (Table 3). If we look at superior and inferior medial wall activations as a group, all subjects showed a focus of activation within the second gyrus anterior to the precentral gyrus during imagery, but only three subjects had a focus during execution. On the other hand, during execution all subjects showed an activation focus in the first gyrus anterior to the precentral gyrus, but only one subject showed activa-

FIG. 5. Sagittal, coronal, and transverse slices of 2 PET comparisons (imagined movements vs. motor preparation and executed vs. imagined movements) in subject 1. Distances of the slices from the AC line and the transverse and sagittal midlines are shown. An omnibus correction was used with a threshold of $P<0.01$. The color code represents the following $z$-values: green, $z \geq 2.8$ and $z<3$; yellow, $z \geq 3$ and $z<4$; and red, $z \geq 4$ (conventions otherwise are as in Fig. 1).

FIG. 6. Sagittal, coronal, and transverse slices of 2 PET comparisons (imagined movements vs. motor preparation and executed vs. imagined movements) in a 2 nd subject, subject 2 (conventions as in Figs. 1 and 5). 
tion during imagery. This pattern was much less pronounced in the right hemisphere (Table 3 ).

The individual results support the group result of a dorsocaudal activation in the parietal lobe during imagery and an additional rostral focus of activation during movement execution. All subjects had foci located in the caudal parts of the left dorsal parietal lobe during imagery, three showed bilateral foci (e.g., subject 1, Fig. 5). All six subjects showed an additional focus of activation during execution versus preparation in the left parietal lobe on the lateral surface of the postcentral sulcus or caudal to the postcentral gyrus, but rostral to the activations observed during imagined movements (e.g., subjects 1 and 2, Figs. 5 and 6). Three showed similar foci of activation in the right hemisphere (e.g., subject 2, Fig. 6).

In the group result, the precuneus was significantly activated by imagined movements only on the right (e.g., Fig. 1 and subject 2, Fig. 6). However, three of the subjects also showed a left hemispheric activation.

Although the significance of group activations is similar for the superior and inferior parietal lobe, only one-half of the subjects had clear individual foci of activation in the inferior parietal lobe during imagined and executed movements. As in the group, these foci were in the dorsal part of the inferior parietal lobe.

In the area of the central sulci, the group pattern was seen in four of the six subjects. For example, in subject 1 during imagined movements, activations in the precentral gyri were clearly located rostral to the central sulcus. During execution of movements, additional activations were seen in the postcentral gyrus (presumably BA 3,2,1, and 5), as well as in the depths of the sulcus. In the other two subjects, activations during imagined movements included not only laterorostral parts of the precentral area but also pre- and postcentral activations deep in the sulcus (e.g., subject 2, Fig. 6). There was, however, a much wider and stronger activation in the later part of the primary sensorimotor area with movement execution (e.g., subject 2, Fig. 6).

In the thalamus and in caudal inferior frontal cortex, we observed a variability of activation pattern that is difficult to explain a posteriori but that we describe here for completeness. The thalamus was activated in only three of the six subjects (e.g., subjects 1 and 2, Figs. 5 and 6), and in these three the locations varied within the thalamus. Relative activations in Broca's area were observed when imagining was compared with execution (Table 2 ). In five of the six subjects, there was activation of area 44 or area 45 when imagining and execution were compared. In three of these, however, the activation was rostral and probably in area 45 . Nevertheless, the coordinates of the group result clearly implicate activation of the caudal inferior frontal cortex (BA 44).

\section{DISCUSSION}

Planning, initiation, and execution of movements constitute three different aspects of motor performance. In animals the anatomy and physiology of these different phases has been studied in detail. The results of these studies suggest that parietal areas are especially associated with spatial aspects of motor planning, whereas the medial and lateral premotor areas are more involved in movement initiation and selection, and the primary sensorimotor cortex has its major role in movement execution (He et al. 1993; Kurata et al. 1988; Passingham 1993). A similar functional division is assumed in humans, supported by the results of lesion studies in patients with premotor and parietal lesions (Freund 1991; Freund and Hummelsheim 1985; Humphrey and Tanji 1991). Lesion studies identify core areas without which the correct performance of a task is not possible. It is likely that during normal motor performance many brain areas are involved, but that the destruction of some of these does not lead to easily detectable impairment of motor function.

We have tried to activate some of these areas sequentially by comparing cerebral activity in the brain associated with each of three components of motor behavior: preparing for, imagining, and executing movements.

We have a special interest in imagined movements. The role of imagined rehearsal in learning and training is well established behaviorally (e.g., Denis 1985; Ryan and Simons 1982), and its effect has been demonstrated quantitatively for simple finger movements (Yue and Cole 1992). What is not well known is the functional anatomy of imagined movements and whether the cerebral areas involved in this behavior are a subset of those responsible for the actual execution of movements.

To address these questions, we chose a motor paradigm that activates the greatest number of movement-associated cortical areas in man, the free selection of a sequence of spatially organized movements (Deiber et al. 1991).

\section{Study design}

One of the difficulties in studying covert motor behavior, such as imagining movements, is that no external control is available to check that subjects perform the tasks or to judge how well they perform them. Therefore precise instructions and good cooperation by subjects are of special importance in such experiments. Some control was provided by the measurements of surface EMG, which monitored for activity in thenar muscles. We registered no movements of the joystick away from the central position during imagining movements, and the surface EMG indicated that, most of the time, muscle activity was comparable with that of the rest state. However, especially at the beginning of scans, subjects could often not avoid minor muscle activation. However, our control condition was "preparation to move" and not rest. We chose preparation to move as the control condition because we wanted to demonstrate that imagining movements is more than simply a readiness to move. During this preparational state, we observed muscle activity especially in proximal muscles in the two subjects studied in more detail outside the scanner. In both subjects this muscle activation was higher than during imagined movements. Our choice of preparatory control had thus two advantages in that it controlled for small muscle activations during imagining and allowed us to dissect out an extra component of movement by making a distinction between preparation and imagery.

\section{Medial premotor activations}

One of our main findings is a differential activation of a more anterior and a more posterior region within the SMA 
during imagining and execution of movements. We know from previous studies that two areas of the medial wall anterior to and posterior to the $\mathrm{AC}$ line can be activated differentially, depending on the exact paradigm (e.g., movement selection: anterior; repetitive cued movements: posterior) and on the patient group (e.g., Parkinsonian patients: less activation in areas anterior to the AC line during freely selected joy-stick movements) (Playford et al. 1992). These data suggest a functional distinction within SMA with the AC line serving as a "border" between anterior SMA and posterior SMA (Passingham 1994). Whereas the anterior part of SMA is thought to be especially associated with the selection of movements, the posterior part is more closely associated with the execution of movements (Passingham 1994).

The findings of our study suggest that there are further functional divisions in the posterior SMA behind the AC line. Both group and individual data support the notion that the more caudal parts are mainly involved in motor execution, whereas more rostral parts are involved in both imagining and executing movements. Individual data show preferential activation of the rostral parts of posterior SMA during imagined movements. This finding fits well with concepts of the SMA that suggest that SMA has both "higher" and "lower" motor functions (e.g., Wiesendanger and Wiesendanger 1984).

When we compared the site of left SMA activations with anatomy in individuals, we found that the two foci are usually situated in two adjacent gyri, both of them anterior to the precentral gyrus but posterior to the $\mathrm{AC}$ line. Thus the functional distinction between a rostral and caudal posterior SMA is mirrored by an anatomic division into two different gyri.

Such functional divisions have been reported in monkeys by Luppino et al. (1991) and by Matsuzaka et al. (1992). They called the more anterior part of SMA pre-SMA. Functionally, the anterior areas show interesting similarities with both the rostral area of posterior SMA and with anterior SMA. It is likely that the division between the caudal and the rostral part of posterior SMA is part of a continuous transition between caudal areas of the medial wall, closely related to motor output functions such as muscle force, and more rostral areas, that are involved in more complex aspects of motor function.

We also found distinct foci of activation in more dorsal and more ventral areas of the medial frontal wall. Whereas motor responses were more closely associated with ventral activations, imagining movements preferentially activated the dorsal area. The location of the ventral area varied with the anatomic variation of the cingulate sulcus in the six subjects. Two of the six subjects had two cingulate sulci, and another three had segments of a second. This corresponds with Ono et al.'s (1990) observation of two such sulci in $\sim 25 \%$ of subjects. If only one cingulate sulcus was seen at the site of activation, then the activation was always above the sulcus; when two were seen, it often lay in the medial wall between the two and in an area just above the top one. The location of the ventral activation foci in relation to cingulate anatomy is similar to that observed by Paus et al. (1993). Because of lack of histological evidence in hu- mans, it is uncertain whether this functional area is a ventral part of SMA or a dorsal part of the cingulate area.

The pattern of activation foci in the individuals showed both a posterior/anterior distinction between imagined and executed movements, and also a difference in ventral/dorsal location. This would suggest a functional division of the medial frontal cortex into a ventrocaudal area, closely related to motor execution and into a dorsorostral area, in this study preferentially activated by imagining movements. This pattern was restricted to the left hemisphere, which may be due to the right-handed performance of the tasks.

\section{Parietal activations-visuomotor integration, shifts of attention, and memory of target coordinates in space}

Imagining and executing movements activates the intermediate and caudal parts of the superior parietal lobe (BA 7 including the precuneus). Grafton et al. (1992) have observed activations of the contralateral dorsal parietal cortex and of the precuneus bilaterally in humans during a cued intermittent tracking task compared with an uncued one. They suggested that this area participates in the integration of spatial attributes during selection of movements. Sergent et al. (1992) asked musicians to read musical notations and translate these notations into keyboard performance. They also observed caudal superior parietal activations and suggested they may reflect the generation of spatial information for the actual motor performance.

Recent PET studies have also implicated the superior parietal lobule in tasks involving visual vigilance (Pardo et al. 1991), spatial selection, and shifts of attention (Corbetta et al. 1993). Pardo et al. (1991) reported localized increases of blood flow in the superior parietal cortex primarily in the right hemisphere during sustained attention to simple visual or somatosensory tasks. Corbetta et al. (1993) observed that superior parietal cortex was more active when attention shifted during a visuospatial task. The increase of rCBF we observe in the superior parietal lobe during imagined movements may, therefore, be associated with visuomotor integration or with shifts of the direction of attention in space.

The activation of the intermediate part of the inferior parietal lobule (dorsocaudal part of the supramarginal gyrus) during motor action and imagery may be related to both spatial and memory components of the task. Decety et al. (1992) have demonstrated activations of the most dorsal part of the inferior parietal lobe when subjects were informed about a movement in space but had to wait before they performed the movements. A similar site of activation with very similar coordinates to ours has been activated by the delayed performance of movements in space when subjects had to hold the "target coordinates" in their mind during scanning (Baker, S., personal communication).

Because subjects had their eyes closed during imagining and executing movements, there was no "new" visual input, so subjects had to rely on a priori knowledge of the spatial dimensions of the required task and the experienced or imagined sensory feedback to perform it correctly. Any form of visuomotor integration during motor imagery or of shifts of attention in space would therefore depend on memorized spatial information. 


\section{Imagined movements and eye movements}

The activation of rostral parts of the posterior SMA and posterior parietal areas during imagined movements raises the question whether eye movements may have been responsible for many of the activations observed during imagined movements. Fox et al. (1985) showed more anterior SMA activations during performance of eye movements compared with more posterior ones during hand movements. Eye movements were not recorded directly in our study. However, we recorded eye movements in six other subjects with the same experimental paradigm and found that the number of eye movements were not significantly different during imagination and execution of the joy-stick movements. The amplitude of such eye movements, during the first two of four 90-s imagery trials, was greater than during the movement task. We found no activation of the frontal eye fields, as defined by the area that is activated, when subjects perform saccades (Anderson et al. 1994). It is therefore unlikely that eye movements were responsible for the major effects observed, although a small contribution from eye movements to the pattern of activity recorded cannot be excluded.

\section{Frontal activations-initiation and selection of movements}

Prefrontal areas, especially BA 9 and 46 in dorsolateral prefrontal cortex (DLPFC), are known to be involved in the selection of movements (Frith et al. 1991). Although the task was externally paced, subjects had to decide in which direction to move or to imagine moving. Compared with motor preparation, there was no significant DLPFC activation during either of the two experimental tasks with spatial selection. The most likely explanation is that DLPFC is already activated during preparation to move. This suggestion is confirmed by results in six subjects who performed a similar motor imagery task compared with rest and whose PET scans demonstrated very significant activity in DLPFC (Ceballos-Baumann, A., personal communication).

Frith et al. (1991) also observed anterior cingulate activation, 15-25 $\mathrm{mm}$ anterior to the $\mathrm{AC}$ line, when comparing willed and instructed action both in a verbal and a sensorimotor task. That result and the results of a word generation experiment (Petersen et al. 1988) suggest that anterior cingulate activity is also associated with response selection and probably attention. We found no statistically significant activations in these anterior cingulate areas when we compared imagining with motor preparation in our study, but there was clear additional activation in an experiment in which motor imagery was compared with rest (Ceballos-Baumann, personal communication).

It is likely that the DLPFC and anterior cingulate are both activated by preparation to move and by motor imagery. The PET technique does not allow us to decide whether the same or different sets of neurons are active during motor preparation and motor imagery in these areas.

\section{Premotor activations}

An important finding is that during imagined movements there was greater activation of ventral opercular premotor areas and of the insula than during preparation. We have previously found a greater and bilateral activation of these areas in patients after stroke (Chollet et al. 1991; Weiller et al. 1992, 1993) and in patients with motorneuron disease (Kew et al. 1993) than in normal subjects. We therefore suggested that the recruitment of these additional motor areas might reflect a mechanism by which the brain adapts to lesions of the corticospinal outflow (Kew et al. 1993; Weiller et al. 1993).

In monkeys, movements of all body parts are represented throughout the insula with upper extremity movements represented more rostrally than those of the lower extremity (Showers and Lauer 1961). Using PET, G. R. Fink, R. S. J. Frackowiak, and R. E. Passingham (unpublished observations ) have demonstrated that in humans the insula and the ventral opercular premotor area contain somatotopically organized motor maps. The activation of insula and ventral premotor areas during imagined and executed movements confirms that activation of these areas is not unique to patients with upper or lower motorneuron lesions, but constitutes part of normal physiological processes. The phenomenon of recruitment in patients may reflect a general pattern of increased activation of motor areas with increasing demand, both in physiological and pathological conditions.

During imagined movements, further activations were observed in the lateral premotor cortex on the dorsal and lateral surface of the superior frontal gyrus. Rao et al. (1993) also observed lateral premotor activations during imagined simple finger movements. Similar to the medial premotor area, execution of movements compared with imagined movements led to a greater activation in the caudal part of the dorsal area of the superior frontal gyrus (Table 2). The caudal part of the activation was continuous with the activation in the precentral gyrus. In the monkey several premotor areas have been described and characterized (e.g., Dum and Strick 1991). However, in man not much is known about the physiological significance of the different lateral premotor areas, and their relationship to other motor areas will have to be addressed in future studies.

\section{Primary sensorimotor areas and motor output}

In the group and in most of the subjects, imagery activated all regions involved in the execution of movements except the primary sensorimotor areas in the central sulcus, posterior SMA and cingulate cortex, somatosensory cortex, and parietal area 5 . All of these have direct corticospinal connections and can thereby influence motor execution directly. But to which aspects of movement are they related? Studies in monkeys have shown that the majority of neurons with direct corticospinal connections in BA 4 encode muscle force and/or change of force (Evarts et al. 1983). A study in which normal volunteers performed a simple finger press with different levels of force (Dettmers et al. 1994) gives similar results. The primary sensorimotor areas, the dorsal bank of the cingulate gyrus, the ventrocaudal part of SMA, and the cerebellar vermis all show a correlation between activation and increasing force. This leads to the conclusion that those cortical areas that are directly associated with the development of muscular force are not primarily involved in motor imagery.

The other region activated only when movements are executed is the dorsal rostral parietal area (BA 5). Dettmers et 
al. (1994) also observed a correlation between the level of activation of this part of the parietal lobe and the degree of applicd force. This increase is presumably due to the increased sensory feedback during motor action.

In the group result and in four of the six subjects, we observed activations during imagined movements on the lateral surface of the precentral gyrus, which is rostrolateral to the precentral areas involved in force generation (Dettmers 1994). We don't know whether this area is still part of the primary motor area or shares functional properties with the premotor areas situated rostral to the precentral sulcus. It is, however, known that the primary motor cortex is also involved in processes other than the direct control of muscle force. Georgopoulos et al. (1993) have shown that populations of neurons that encode the direction of movement can also been found in the motor cortex. It is possible that these neurons could become active during imagined movements without necessarily changing levels of muscle activity. This idea would also be compatible with the observation in two subjects (e.g., subject 2, Fig. 6), who showed clear activation of primary motor areas in the depth of the central sulcus, without activation of the more caudal parts of SMA or cingulate cortex, during imagined movements.

\section{Imagined movements - a subsystem of motor behavior}

By controlling out the "preparatory component" we have demonstrated areas that are directly concerned with motor imagery. Because these areas are also involved in the execution of movements, they can be seen as a subsystem of the cortical network involved in motor behavior (Table 1). These results are analogous to observations in the language sphere by Wise et al. (1991) during a verb generation task without vocalization, when subjects thought of words without speaking them. They found activation of prefrontal and premotor areas that they associated with a network involved in speech production. Similarly, Roland and Friberg (1985) suggested that part of the network normally activated by processing of visual information might be activated by visual imagery.

\section{Motor recovery and motor learning}

We began this study because of our interest in recovery of function after brain injury. Activation patterns in patients are confounded by poor performance in those with incomplete recovery. This study has shown that many brain areas are activated by motor tasks even when subjects do not move. Knowledge of these activation patterns should allow us to investigate and interpret patterns of activation in patients more easily and rationally.

The results of this study also help to explain why motor imagery can improve motor performance. There has been speculation that imagined and actual movements may share a common physiological substrate (e.g., Kohl and Roenker 1989). We have shown that this is the case.

We thank our volunteers, the members of the Positron Emission Tomography Methods section of the Medical Research Council Cyclotron Unit and the radiographers $\mathrm{G}$. Lewington and A. Williams without whom these studies would not have been possible.

K. M. Stephan was supported by the Wellcome Trust.
Address for reprint requests: R. S. J. Frackowiak, MRC Cyclotron Unit, Hammersmith Hosp., Ducane Road, London W12 ONN, UK.

Received 6 April 1994; accepted in final form 30 August 1994. NOTE ADDED IN PROOF

A brief communication by Tyszka et al. using functional MR, published after submission of this article, supports our notion of distinct foci of activation within the medial wall during imagined and executed movements (Ann. Neurol. 35: 746-749, 1994).

\section{REFERENCES}

Anderson, T. J., Jenkins, I. H., Brooks, D. J., Hawken, M., Frackowiak, R. S. J., AND KeNNARD, C. Cortical control of saccades and fixation in man: a PET study. Brain. In press.

Chollet, F., Di Piero, V., Wise, R. S. J., Brooks, D. J., Dolan, R. J., AND FRACKOWIAK, R. S. J. The functional anatomy of motor recovery after stroke in humans: a study with positron emission tomography. Ann. Neurol. 29: 63-71, 1991.

Corbetta, M., Miezin, F. M., Shulman, G. L., and Petersen, S. E. A PET study of visuospatial attention. J. Neurosci. 13: 1202-1226, 1993.

Decety, J., Kawashima, R., Gulyas, B., AND Roland, P. E. Preparation for reaching: a PET study of the participating structures in the human brain. NeuroReport 3: 761-764, 1992.

DECETY, J., PHILIPPON, B., AND INGVAR, D. H. rCBF landscapes during motor performance and motor ideation of a graphic gesture. Eur. Arch. Psychiatry Neurol. Sci. 238: 33-38, 1988.

Deiber, M.-P., Passingham, R. E., Colebatch, J. G., Friston, K. J., NIXON, P. D., AND FRACKOWIAK, R. S. J. Cortical areas and the selection of movement: a study with positron emission tomography. Exp. Brain Res. 84: 393-402, 1991.

DENIS, M. Visual imagery and the use of mental practice in the development of motor skills. Can. J. Appl. Sport Sci. 10: 4S-16S, 1985.

Dettmers, C., Fink, G. R., Lemon, R., Stephan, K. M., Passingham, R. E., AND FrackowiaK, R. S. J. Motor area in man in the caudal bank of the cingulate sulcus. Proc. IVth Meeting Eur. Neurol. Soc., Barcelona J. Neurology 241, Suppl. 1: S157, 1994.

DUM, R. P. AND STRICK, P. L. The origin of corticospinal projections from the premotor areas in the frontal lobe. J. Neurosci. 11: 667-689, 1991.

Evarts, E. V., Fromm, C., Kröller, J., AND Jennings, V. A. Motor cortex control of finely graded forces. J. Neurophysiol. 49: 1199-1215, 1983.

FoX, P. T., FoX, J. M., RAIChlE, M. E., AND BuRDE, R. M. The role of cerebral cortex in the generation of voluntary saccades: a positron emission tomographic study. J. Neurophysiol. 54: 348-369, 1985.

Fox, P. T., Mintum, M. A., Raichle, M. E., Miezin, F. M., Allman, J. M., AND VAN EsSEN, D. C. Mapping human visual cortex with positron emission tomography. Nature Lond. 323: 806-809, 1986.

FreUND, H.-J. What is the evidence for multiple motor areas in the human brain? In: Motor Control: Concepts and Issues, edited by D. R. Humphrey and H.-J. Freund. New York: Wiley, 1991, p. 399-411.

FREUND, H. J. AND HUMMELSHEIM, H. Lesions of premotor cortex in man. Brain 108: 697-733, 1985.

Friston, K. J., Frith, C. D., Liddle, P. F., Dolan, R. J., Lammertsma, A. A., AND FRACKOWIAK, R. S. J. The relationship between global and local changes in PET scans. J. Cereb. Blood Flow Metab. 10: 458-466, 1990.

Friston, K. J., Frith, C. D., Liddle, P. F., and Frackowiak, R. S. J. Plastic transformation of PET images. J. Comput. Assisted Tomogr. 15: 634-639, 1991a.

Friston, K. J., Frith, C. D., Liddle, P. F., and Frackowiak, R. S. J. Comparing functional (PET) images: the assessment of significant change. J. Cereb. Blood Flow Metab. 11: 690-699, 1991 b.

Frith, C. D., Friston, K., LidDLE, P. F., AND FrackowiaK, R. S. J. Willed action and the prefrontal cortex in man: a study with PET. Proc. R. Soc. Lond. B Biol. Sci. 244: 241-246, 1991.

Georgopoulos, A. P., TAIRA, M., AND LuKashin, A. Cognitive neurophysiology of the motor cortex. Science Wash. DC 260: 47-52, 1993.

Grafton, S. T., Mazziotta, J. C., Woods, R. P., and Phelps, M. E. Human functional anatomy of visually guided finger movements. Brain 115: 565-587, 1992.

HALl, C., BUCKHOlz, E., AND FishBURNE, G. J. Imagery and the acquisition of motor skills. Can. J. Appl. Sport Sci. 17: 19-27, 1992.

HE, S.-Q., DuM, R. P., AND STRICK, P. L. Topographic organization of 
coricospinal projections from the frontal lobe: motor areas on the lateral surface of the hemisphere. J. Neurosci. 13: 952-980, 1993.

HUMPHREY, D. R. AND TANJI, J. What features of voluntary motor control are encoded in the neuronal discharge of different cortical motor areas? In: Motor Control: Concepts and Issues, edited by D. R. Humphrey and H.-J. Freund. New York: Wiley, 1991, p. 413-443.

Jenkins, I. H., BRooks, D. J., Nixon, P. D., Frackowiak, R. S. J., AND Passingham, R. E. Motor sequence learning: a study with positron emission tomography. J. Neurosci. 14: 3775-3790, 1994.

Kew, J. J. M., Leigh, P. N., Playford, E. D., Passingham, R. E., Goldstein, L. H., Frackowiak, R. S. J., and Brooks, D. J. Cortical function in amyotrophic lateral sclerosis. A positron emission tomography study. Brain 116: 655-680, 1993.

KOHL, R. M. AND RoENKER, D. L. Behavioral evidence for shared mechanisms between actual and imaged motor responses. J. Hum. Mov. Stud. 17: 173-186, 1989.

KURATA, K. AND WISE, S. P. Premotor cortex in rhesus monkeys: neuronal activity during externally and internally instructed motor tasks. Exp. Brain Res. 72: 237-248, 1988.

Lang, W., Petit, L., Höllinger, P., Pietrzyk, U., Tzourio, N., Mazoyer, B., AND BERTHOZ, A. A positron emission tomography study of oculomotor imagery. NeuroReport 5: 921-924, 1994.

luppino, G., Matelli, M., Camarda, R. M., Gallese, V., and Rizolatti, G. Multiple representations of body movements in mesial area 6 and the adjacent cingulate cortex: an intracortical microstimulation study in the macaque monkey. J. Comp. Neurol. 311: 463-482, 1991.

Matsuzaka, Y., Aizawa, H., ANd Tanj, J. A motor area rostral to the supplementary motor area (presupplementary motor area) in the monkey: neuronal activity during a learned motor task. J. Neurophysiol. 68: 653662, 1992.

OLDFIELD, R. C. The assessment and analysis of handedness: the Edinburgh inventory. Neuropsychologia 9: 97-113, 1971.

Ono, M., Kubik, S., AND Abernathey, C. D. Atlas of the Cerebral Sulci. Stuttgart, Germany: Thieme, 1990.

PARDO, J. V., FoX, P. T., AND RaICHLE, M. E. Localization of a human system for sustained attention by positron emission tomography. Nature Lond. 349: 61-64, 1991.

Passingham, R. E. The frontal lobes and voluntary action. In: Oxford Psychology Series 21. Oxford, UK: Oxford Science Publications, 1993, p. $1-299$.

Passingham, R. E. The status of the premotor areas: evidence from PET scanning. In: Neuronal Control of Movement, edited by W. R. Ferrell and U. Protke. New York: Raven. In press.

Paus, T., Petrides, M., Evans, A. C., AND Meyer, E. Role of the human anterior cingulate cortex in the control of oculomotor, manual, and speech responses: a positron emission tomography study. J. Neurophysiol. 70 : 453-467, 1993.

Petersen, S. E., Fox, P. T., Posner, M. I., Mintun, M., and Raichle, M. E. Positron emission tomographic studies of the cortical anatomy of single-word processing. Nature Lond. 331: 585-589, 1988.

Playford, E. D., Jenkins, I. H., Passingham, R. E., Nutt, J., FrackoWIAK, R. S. J., AND BROOKS, D. J. Impaired mesial frontal and putamen activation in Parkinson's disease: a positron emission tomography study. Ann. Neurol. 32: 151-161, 1992.

RAICHLE, M. E. Circulatory and metabolic correlates of brain function in normal humans. In: Handbook of Physiology. The Nervous System. Higher Functions of the Brain. Bethesda, MD: Am. Physiol. Soc., 1987, vol. 5, p. 643-674.

Rao, S. M., Binder, J. R., Bandettini, P. A., HammeKe, T. A., YetKin, F. Z., JeSMANOWICZ, A., LISK, L. M., MORRIS, G. L., MUELleR, W. M., EstKowski, R. T. R., Wong, E. C., Haughton, V. M., and Hyde, J. S. Functional magnetic resonance imaging of complex human movements. Neurology 43: 2311-2318, 1993.

RoBB, R. A. A software system for interactive and quantitative analysis of biomedical images. In: 3D Imaging in Medicine, edited by $\mathrm{K}$. H. Höhne, H. Fuchs, and S. M. Pizer. NATO ASI Series, 1990, vol. F60, p. 333361 .

ROLAND, P. E. AND FRIBERG, L. Localisation of cortical areas activated by thinking. J. Neurophysiol. 53: 1219-1243, 1985.

Roland, P. E., LARSEn, B., Lassen, N. A., AND SKInhoJ, E. Supplementary motor area and other cortical areas in organisation of voluntary movements in man. J. Neurophysiol. 43: 118-136, 1980.

RYAN, E. D. AND SIMONS, J. Efficacy of mental imagery in enhancing mental rehearsal of motor skills. J. Sport Psychol. 4: 41-51, 1982.

Schachter, S. C., Ransil, B. J., AND Geschwind, N. Associations of handedness with hair color and learning disabilities. Neuropsychologia 25: 269-276, 1987.

Sergent, J., Zuck, E., Terriah, S., And MacDonald, B. Distributed neural network underlying musical sight-reading and keyboard performance. Science Wash. DC 257: 106-109, 1992.

Shallice, T., Fletcher, P., Frith, C. D., Grasby, P., Frackowiak, R. S. J., AND DOLAN, R. J. The brain regions associated with the acquisition and retrieval of verbal episodic memory. Nature Lond. 368: 633635, 1994.

Showers, M. J. C. AND LAUER, E. W. Somatovisceral motor patterns in the insula. J. Comp. Neurol. 117: 107-115, 1961.

Silbersweig, D. A., Stern, E., Frith, C. D., Cahill, C., Schnoor, L., Groontoonk, S., Spinks, T., Clark, J., Frackowiak, R. S. J., AND JONES, T. Detection of thirty-second cognitive activations in single subjects with positron emission tomography: a new low-dose $\mathrm{H}_{2}{ }^{15} \mathrm{O}$ regional cerebral blood flow three-dimensional imaging technique. J. Cereb. Blood Flow Metab. 13: 617-629, 1993.

Spinks, T. J., Jones, T., Bailey, D. L., Townsend, D. W., Grootoonk, S., Bloomfield, P. M., Gilardi, M. C., Casey, M. E., SiPe, B., and REED, J. Physical performance of a positron tomograph for brain imaging with retractable septa. Phys. Med. Biol. 37: 1637-1655, 1992.

Townsend, D. W., Geisbuhler, A., Defrise, M., Hoffman, E. J., Spinks, T. J., BAILEY, D. L., GILARDI, M. C., AND JonES, T. Fully three-dimensional reconstruction for a PET camera with retractable septa IEEE. Trans. Med. Imag. 10: 505-512, 1991.

TAlairach, J. AND TouRnOux, P. Co-Planar Stereotaxic Atlas of the Human Brain. Stuttgart, Germany: Thieme, 1988.

Watson, J. D. G., MYers, R., Frackowiak, R. S. J., Hajnal, J. V., Woods, R. P., Mazziotta, J. C., ShIPP, S., AND ZeKI, S. Area V5 of the human brain: evidence from a combined study using positron emission tomography and magnetic resonance imaging. Cereb. Cortex 3: 79-94, 1993.

Weiller, C., Chollet, F., Friston, K. J., Wise, R. J. S., and Frackowiak, R. S. J. Functional reorganisation of the brain in recovery from striatocapsular infarction in man. Ann. Neurol. 31: 463-472, 1992.

Weiller, C., Ramsay, S. C., Wise, R. J. S., Friston, K. J., and FrackoWIAK, R. S. J. Individual patterns of functional reorganisation in the human cerebral cortex after capsular infarction. Ann. Neurol. 33: 181$189,1993$.

WiesENDANGER, M. AND WIESENDANGER, R. The supplementary motor cortex in the light of recent investigations. Exp. Brain Res. Suppl. 9: 382392, 1984.

Wise, R., Chollet, F., Hadar, U., Friston, K., HoffNer, E., and FrackoWIAK, R. Distribution of cortical neural networks involved in word comprehension and word retrieval. Brain 114: 1803-1817, 1991.

Woods, R. P., Cherry, S. R., ANd Mazziotta, J. C. Rapid automated algorithm for aligning and reslicing PET images. J. Comput. Assisted Tomogr. 16: 620-633, 1992.

Woods, R. P., MAZZIOTTA, J. C., AND CHERRY, S. R. MRI-PET registration with automated algorithm. J. Comput. Assisted Tomogr. 17: 536-546, 1993.

YuE, G. AND COLE, K. J. Strength increases from the motor program: comparison of training with maximal voluntary and imagined muscle contractions. J. Neurophysiol. 67: 1114-1123, 1992. 